\title{
Male involvement in breastfeeding promotion and protection: an assessment of male undergraduates' views in Sagamu, southwest Nigeria
}

\author{
Sholeye $\mathrm{OO}^{1}$, Otenaike $\mathrm{PO}^{2}$, Runsewe-Abiodun $\mathrm{TI}^{1}$
}

${ }^{1}$ Obafemi Awolowo College of Health Sciences, Olabisi Onabanjo University, Sagamu Campus, Ogun State, Nigeria

${ }^{2}$ Department of Internal Medicine Federal Medical Center, Abeokuta, Ogun State, Nigeria

Submitted: $28^{\text {hh }}$ April 2021

Accepted: $10^{\text {th }}$ June 2021

Published: $30^{\text {th }}$ June 2021

\begin{abstract}
Objective: Breastfeeding is a cost-effective and evidence-based public health intervention for the control of childhood malnutrition and its consequences. Partners' support and attitude towards breastfeeding is an important determinant of breastfeeding initiation, continuity, and outcome. This study assessed the perception of breastfeeding and its support among male students in Sagamu, Nigeria.

Method: A cross-sectional study was carried out among 300 male undergraduate students in Sagamu, selected via systematic sampling. Data were collected with the aid of a structured, self-administered questionnaire and analyzed using SPSS 21.0 , with results presented as frequencies and proportions.

Result: The mean age of respondents was $20 \pm 3.5$ years. All respondents felt it was important for women to breastfeed their infants; $42 \%$ of respondents felt breastfeeding interfered with work; $20 \%$ felt women should be entitled to paid maternity leave; $85 \%$ will support efforts to promote breastfeeding in public; $95 \%$ will encourage their partners to breastfeed while working outside the home; $92 \%$ will assist their breastfeeding partners with household chores.

Conclusion: Respondents had a good perception of breastfeeding and were willing to support its practice at home, work, and in the community. Adequate engagement of men in nutrition education activities will be most effective in promoting and protecting breastfeeding.
\end{abstract}

Keywords: breastfeeding, male, young, adult, perception, support, Sagamu.

\section{Plain English Summary}

Breastfeeding is an evidence-based preventive strategy for addressing childhood malnutrition. Male involvement and partner support are essential for promoting and sustaining breastfeeding. This study assessed the views of male undergraduates in Sagamu, Ogun State. All participants viewed breastfeeding as a positive and necessary activity. They were willing to support their partners throughout breastfeeding and also get involved in its promotion in the larger society.

\section{Introduction}

In recent years, malnutrition has been viewed as an economic, social, and developmental issue in addition to its traditional health-based focus. Considerable evidence exists on the impact of adequate nutrition on socio-economic and human capital development (1). Optimal nutrition in childhood is the main strategy for combating some of the challenges threatening child survival in many parts of the developing world including sub-Saharan Africa and Southeast Asia. This has necessitated a 
renewed focus on infant and young child feeding, as well as other aspects of childhood nutrition by the United Nations and other stakeholders (1).

The significant childhood morbidity and mortality recorded in sub-Saharan Africa, which has remained a cause for concern, is partly preventable by adequate nutrition and feeding practices, including optimal breastfeeding. The importance of nutrition in the first one thousand days of life to the overall quality of life of individuals has been well documented in the medical literature $(2,3)$. Optimal breastfeeding and complementary feeding are the fulcra of adequate infant and young child nutrition in the first two years of life. Breastfeeding is an evidence-based, cost-effective public health intervention for the overall wellbeing and survival of children (4). There is overwhelming evidence of its benefits to both mother and child, including increased intellectual capacity, reduction in the episodes of acute respiratory infections, diarrhea, otitis media, and other childhood illnesses (5). Despite the outlined evidence-based benefits, breastfeeding rates have remained sub-optimal all over the world, with wide disparity across and within regions (6). The prevalence of exclusive breastfeeding in sub-Saharan Africa has been low. In Nigeria, only $29 \%$ of infants were exclusively breastfed in contrast to Ethiopia, where $59.9 \%$ of infants were exclusively breastfed $(5,7)$. Several reasons have been given for this including maternal occupation, household chores, pressure from grandmothers and other relatives as well as very little support from husbands or partners $(7,8)$.

Initiation and sustenance of breastfeeding have been strongly linked to having adequate partner support. When not involved, a good number of men felt left out of the breastfeeding process (9). The attitude and actions of fathers have been demonstrated to affect women's intentions and actual breastfeeding practices, including duration and form (mixed, predominant, or exclusive) $(10,11)$. Furthermore, there is scientific evidence of the role of paternal support as the main predictor of exclusive and optimum breastfeeding (12). Fathers who identify their roles as very important and contributory to the overall wellbeing of mother and baby are more likely to provide the needed enabling environment for their wives to breastfeed and carry out other child care activities $(13,14)$.

In many African climes, men are traditionally in positions of leadership and influence at home, the larger community, and the workplace. Therefore, it is very important to address any misconceptions and negative attitudes towards breastfeeding and infant feeding, among them (15). Breastfeeding and other aspects of infant feeding are mostly taught to mothers and women of reproductive age at various healthcare facilities, with little or no education provided for the expectant fathers (9). The Innocenti Declaration encourages a multisectoral and holistic approach to promoting, protecting, and sustaining breastfeeding. It recognizes the potential benefits of adequate engagement of all stakeholders in advocating for optimal breastfeeding and infant feeding (16). The breastfeeding situation in Nigeria needs significant improvement, with a need for a multi-pronged approach, if the global target of $50 \%$ exclusive breastfeeding rate is to be attained $(1,17)$. A lot of interventions have targeted women of reproductive age, often forgetting the significant others. It is therefore imperative that issues bordering on men's commitment to breastfeeding be brought to the fore. Most male undergraduate students are young adults who are yet to experience fatherhood but may hold several views on the importance or otherwise of breastfeeding, which may influence their future decisions on infant feeding. To the best of our knowledge, no study has sought the views of young men on breastfeeding and its promotion in southwest Nigeria. This study assessed the perception of breastfeeding and support for its promotion, among young adult males in Sagamu, southwestern Nigeria.

\section{Methodology}

Sagamu Township is an urban area located within the larger Sagamu Local Government Area (LGA) of Ogun State, southwestern Nigeria. The LGA consists of fifteen wards and has a population of about 360,000 people, as at the 2006 population census. It is a heterogeneous society, with people of diverse ethnic groups and vocations. The predominant language spoken is Yoruba, particularly the ljebu (Remo) dialect. Obafemi Awolowo College of Health Sciences, a campus of Olabisi Onabanjo University, and its affiliated teaching hospital (Olabisi Onabanjo University Teaching Hospital) is located within the township. The Sagamu campus houses three faculties of the university namely - Pharmacy, Basic Medical Sciences, and Clinical Sciences. These faculties have at least six departments in each of them, with students at various levels of study.

A cross-sectional descriptive study was carried out among male undergraduate students of the faculties of pharmacy and basic medical 
sciences on the Sagamu campus, between February and March 2018. Only male returning students in their third and fourth years, without children of their own, were recruited into the study. Using the sample size determination formula for descriptive studies (17), with a prevalence of $29 \%$ from a previous nationwide survey (7), a sample size of 300 was calculated, allowing for $10 \%$ non-response. Respondents were selected using a multi-stage sampling technique. It involved stratification of the study population into the two levels (third and fourth years) to be recruited. This was followed by a proportionate allocation of the sample to each faculty and the respective levels of study. For students in the Faculty of Basic Medical Sciences, the proportionate allocation was made to represent the four departments. Respondents were finally selected by systematic sampling. Data were collected with the aid of a semi-structured, self-administered questionnaire made of three sections - sociodemography; perception of breastfeeding; and willingness to support breastfeeding. It was pretested in another public university in southwest Nigeria, following which necessary adjustments were made to the study instrument. Data analysis was carried out using the statistical package for social sciences (SPSS) version 20.0. Frequencies and proportions were calculated and presented. The perception was assessed on a 16-point scale. Positive responses (those supportive of breastfeeding) were awarded one point $(+1)$ each while inappropriate responses scored zero. Scores below $8(50 \%)$ were categorized as poor, while those from 8 and above were graded as good.

\section{Results}

\section{Socio-demographic characteristics of respondents}

One hundred and twenty (40\%) respondents were aged 16-20years; 117 (39\%) were aged 21-25years; while $63(21 \%)$ were aged 26 30 years. The mean age of respondents was $20 \pm 3.5$ years. Students of Yoruba ethnic extraction constituted $272 \quad(90.7 \%)$ of respondents; $180(60 \%)$ respondents were Christians; $210(70 \%)$ had fathers with tertiary education and a majority (95\%) of respondents were single.

\section{Perception of breastfeeding and work}

Forty-five (15\%) respondents thought that women who intended to practice exclusive breastfeeding should not work outside the home; $90 \%$ of respondents believed breastfeeding women should be provided additional breaks at work and it should be an institutional policy; $20 \%$ of respondents thought women should be allowed paid maternity leave; the majority $(90.3 \%)$ of respondents felt breastfeeding breaks should be an institutional policy for concerned mothers; $66.7 \%$ of respondents believed that exclusive breastfeeding should attract a longer period of paid maternity leave. Provision of facilities for promotion of breastfeeding at the workplace was seen as something unwarranted by $47.7 \%$ of respondents; $42 \%$ were convinced that breastfeeding negatively influences productivity at work, and $90.3 \%$ thought that women should ask potential employers if breastfeeding breaks are allowed or supported in the organization (Table 1).

Table 1: Respondents' views on breastfeeding and the world of paid work

\begin{tabular}{lcc}
\hline \multicolumn{1}{c}{ Statement } & \multicolumn{2}{c}{ Response } \\
& Yes & No \\
& $\mathbf{F ~ ( \% )}$ & $\mathbf{F ~ ( \% )}$ \\
\hline It is important for a woman to breastfeed her baby & $300(100.0)$ & $0(0.0)$ \\
Breastfeeding mothers should not work outside the home & $45(15.0)$ & $255(85.0)$ \\
Women should not express milk or breastfeed at work & $141(47.0)$ & $159(53.0)$ \\
Breastfeeding decreases productivity at work & $126(42.0)$ & $174(58.0)$ \\
Breastfeeding breaks should be an institutional policy & $271(90.3)$ & $29(9.7)$ \\
Women are entitled to paid maternity leave & $60(20.0)$ & $240(80.0)$ \\
Exclusive breastfeeding should attract longer maternity leave & $200(66.7)$ & $100(33.3)$ \\
Women should ask if breastfeeding is allowed at work & $271(90.3)$ & $29(9.7)$ \\
The provision of a feeding room at work is a waste of resources & $60(20.0)$ & $240(80.0)$ \\
Breastfeeding at work taints the image of an organization & $143(47.7)$ & $157(52.3)$ \\
\hline
\end{tabular}

\section{Perception about breastfeeding and the society}

All respondents believed it was important for a woman to breastfeed her infant; $47.3 \%$ thought it should not be done in public for a few reasons, such as it is embarrassing to passersby $46 \%$; indecent exposure $11.2 \%$. The majority $(90.3 \%)$ of respondents thought that males should encourage women who desire to breastfeed; $70 \%$ felt men should assist their 
breastfeeding partners or other mothers in expressing breast milk; $80.3 \%$ of respondents opined that male community leaders should actively support breastfeeding at every given opportunity. All respondents $(100 \%)$ believed that government policies and programs should protect, promote and support breastfeeding (Table 2). Respondents' perception of breastfeeding: $66 \%$ of participants had a good perception of breastfeeding.

Table 2: Respondents' views on breastfeeding and the larger society

\begin{tabular}{lcc}
\hline \multicolumn{1}{c}{ Statement } & \multicolumn{2}{c}{ Response } \\
& Yes & No \\
& $\mathbf{F ~ ( \% )}$ & $\mathbf{F ~ ( \% )}$ \\
\hline Men should encourage women willing to breastfeed & $271(90.3)$ & $29(9.7)$ \\
Men should assist partners in expressing breast milk & $210(70.0)$ & $90(30.0)$ \\
Men should assist nursing mothers with household chores & $240(80.0)$ & $60(20.0)$ \\
Government policies should promote and sustain breastfeeding & $300(100.0)$ & $0(0.0)$ \\
everywhere & & \\
Male community leaders should support breastfeeding & $241(80.3)$ & $59(19.7)$ \\
Women should not breastfeed in public & $142(47.3)$ & $158(52.7)$ \\
Reasons why women shouldn't breastfeed in public & $\mathrm{n}=142$ & \\
It is unattractive and unsightly & $61(42.8)$ & \\
It is an embarrassment to passers-by & $65(46.0)$ & \\
It constitutes indecent exposure & $16(11.2)$ & \\
\hline
\end{tabular}

Support for breastfeeding and its promotion Two hundred and fifty-two (84\%) respondents expressed willingness to support their partners to breastfeed their children; $95 \%$ will encourage their partners to breastfeed while working outside the home; $90 \%$ will assist their partners to express breast milk for their baby; $92 \%$ will assist their partners or significant other with household chores. As many as $90 \%$ of respondents were willing to support community-based breastfeeding promotion programs; $85 \%$ will gladly support efforts to promote breastfeeding in public places; $91 \%$ of respondents will support women to breastfeed in the workplace.

One hundred and eighty-five respondents $(61.7 \%)$ will only encourage their partners to work for organizations with breastfeeding facilities; $42.7 \%$ will have their partners interviewed for jobs only at companies that allow breastfeeding at work (Table 3).

Table 3: Respondents' views on support for Breastfeeding

\begin{tabular}{lcc}
\hline \multicolumn{1}{c}{ Statement } & \multicolumn{2}{c}{ Response } \\
& Yes & No \\
& $\mathbf{F ~ ( \% )}$ & $\mathbf{F ~ ( \% )}$ \\
\hline Assist significant other to breastfeed a child & $252(84.0)$ & $48(16.0)$ \\
Encourage partner to breastfeed while working outside the home & $285(95.0)$ & $15(5.0)$ \\
Assist partner to express breast milk for our baby & $270(90.0)$ & $30(10.0)$ \\
Allow partner work in only organizations with breastfeeding room & $185(61.7)$ & $115(38.3)$ \\
Partner will only interview for positions in offices where breastfeeding is allowed & $128(42.7)$ & $172(57.3)$ \\
Will support women to breastfeed in the workplace & $273(91.0)$ & $27(9.0)$ \\
Support efforts to promote breastfeeding in public places & $255(85.0)$ & $45(15.0)$ \\
Support community-based breastfeeding programs & $270(90.0)$ & $30(10.0)$ \\
Assist partner with household chores while breastfeeding & $276(92.0)$ & $24(8.0)$ \\
\hline
\end{tabular}

\section{Discussion}

The overwhelming evidence of the immense benefits of breastfeeding to maternal and child wellbeing in the medical literature is an opportunity for result-oriented and sustainable interventions $(18,19)$. While it is important to encourage and empower mothers to optimally breastfeed their infants and young children, the influence of others in the community must be taken into consideration. The roles played by significant others (including spouses or partners) in breastfeeding decision-making, initiation, and sustenance have been well documented in literature over the years $(9,20$, 21).

The importance attached to breastfeeding by all participants in this present study reflects the age-long premium placed on breastfeeding in many African societies, where it is considered an essential cultural practice $(21,22)$. This is consistent with findings from previous studies among men and several other members of 
various communities within and outside subSaharan Africa $(13,24,25)$. It is also in support of several international and national documents that state explicitly the importance of breastfeeding to both mother and child health while encouraging health workers to promote the same $(5,19,26)$.

Although a majority $(85 \%)$ of the respondents felt working mothers could practice exclusive breastfeeding, the proportion who held on to the disturbing view of the inability to combine paid employment and exclusive breastfeeding was worrisome. This is more so because such opinions may negatively influence women's decisions on infant feeding. Mothers may therefore not be adequately motivated to breastfeed their infants exclusively for the full duration of six months if their significant others held on to such views $(11,12)$. It however contrasts with findings from a study among males in a tertiary institution in southwest Nigeria, where only $21.8 \%$ felt it was possible to carry out exclusive breastfeeding (25). The observed disparity may be due to a difference in population characteristics since this study was conducted entirely among undergraduate students who are mostly single in contrast to that from Ibadan which was among male staff, many of whom were experienced in infant feeding as fathers. It is very important to note that the demands of work are a major reason for the discontinuation of breastfeeding by many mothers in developing countries like Nigeria $(20,27)$. Availability of paid maternity leave, paid breastfeeding breaks and child care facilities, provided by the employer at the workplace, encourage mothers to practice exclusive breastfeeding and sustain it optimally until two years and beyond (4). However, the proportion of study participants who felt women were entitled to paid maternity was very low $(20 \%)$. The implication of this has been documented in a previous study in north-central Nigeria in which the absence of paid maternity leave was a barrier to exclusive breastfeeding (27).

A major accomplishment of the International Labour Organization (ILO) over a century ago, was recognition of the peculiar needs of nursing mothers (28). However the responses of a significant proportion of study participants concerning breastfeeding at work, the productivity of breastfeeding mothers, and the impact of breastfeeding on an organization's image, were clearly at variance with the ILO convention and the detailed work of UNICEF \& WHO $(19,28)$. The viewpoints expressed by some respondents were reflective of the negative pressure women face at work after returning from their maternity leave, particularly when colleagues are uncooperative and insensitive $(27,29)$. Women have called for an enabling work environment that promotes breastfeeding, stating that work productivity will improve rather than decrease, with adequate support, as perceived by over $50 \%$ of our study participants $(29,30,31)$. The Innocenti Declaration (1990) along with the follow-up declaration fifteen years later, on infant and young child feeding, clearly calls for the elimination of all obstacles to successful breastfeeding in the health system and workplace, through adequate stakeholder engagement (32).

Cultural influences play a role in breastfeeding promotion or otherwise in many traditional societies. In some settings, men still believe that breastfeeding is strictly the business of mothers and that they play no role in the decision-making process regarding infant feeding $(10,15,20)$. This study, however, shows a very large proportion of respondents being of the view that women should be encouraged to breastfeed and men should assist their partners in every way they can, including with household chores. This is in agreement with previous works on male involvement in breastfeeding $(13,14,25)$. In line with our findings, a study from Tanzania reported how fathers highly valued breastfeeding and put in great effort to make it easy and successful for the whole family. ${ }^{11}$ Men may need only a little encouragement from healthcare providers to be more interested in the baby's feeding and wellbeing so that decision-making concerning the baby is a joint venture $(9,14)$.

The public image of breastfeeding has left more controversies than answers regarding its acceptance or otherwise. While it is most desirable for women to use designated feeding rooms when outside the home, some form of breastfeeding will inevitably happen in public. A situation in which almost half of our respondents felt it was inappropriate for a woman to breastfeed in public reflects the negative perception of the art in society. It buttresses findings from previous studies in which males would rather have ladies expose some parts of their breasts than a woman breastfeeding in a public space $(23,32)$. It is similar to the views expressed by fathers in a previous study, in which many were uncomfortable with mothers' public display of breastfeeding (10). The perception of breastfeeding as unsightly, embarrassing, or indecent exposure is consistent with findings from a previous study among young men in the 
United States (24). However, young men have also been documented to have positive attitudes towards breastfeeding after observing two or more women breastfeed their infants (33). The Innocenti declaration calls for the reinforcement of breastfeeding culture in all communities, thereby necessitating coordinated efforts to assist women to become self-confident and efficient in all aspects of breastfeeding, even when in public (32). The perception of study participants towards breastfeeding was good in contrast to findings from Ibadan, southwest Nigeria where less than a quarter of respondents had a positive perception towards infant feeding. The observed difference may be because participants in this study were mostly unmarried undergraduate health sciences students and therefore had little or no practical experiences as fathers or partners compared with the married, working-class in Ibadan (25).

Support for breastfeeding in this study was predominantly good, with participants willing to promote policies, community efforts and carry out activities that will encourage women to breastfeed their infants. This is similar to findings from previous studies carried out in other countries, where men actively supported their partners in the breastfeeding process and advocated for community efforts towards the promotion and protection of breastfeeding (13, 14). A previous study reported more support for breastfeeding among younger men compared with the older study participants (15). The vital role played by fathers or partners in supporting their breastfeeding spouses is a determinant of positive breastfeeding outcomes. The confident father will more likely record greater success in breastfeeding promotion at home and the community (13).

With considerable evidence that lack of family support particularly from the husband or partner hurts breastfeeding intention, initiation, and duration (27), efforts towards male involvement in breastfeeding should be increased. Oftentimes attitudes towards breastfeeding are formed before men attain fatherhood, which may be due to cultural influences or even the messages delivered by the media (34). The Global Breastfeeding Collective, led by UNICEF and WHO is advocating for increased support for breastfeeding. In particular, the role of partners should be acknowledged employing a paternity leave, in addition to the established paid maternity leave and adequate community mobilization (35).

Apart from being the first survey among intending fathers in our region of Nigeria, this study presents a unique body of information on the thoughts and commitment of young adult males to breastfeeding and its promotion. It further adds to the evidence that the breastfeeding narrative by the mainstream media may need to change to highlight the very important roles men play in the initiation, sustenance, and outcomes of breastfeeding. Nurses, doctors, and other allied health professionals need to empower women and men to adequately nourish their infants and young children as a health promotion strategy (3). The goals and objectives of the Innocenti Declaration remain relevant even after three decades. It is only when every member of the community is empowered to protect and support breastfeeding that the global target of $50 \%$ prevalence for exclusive breastfeeding, can be reached (35). As often as possible, health workers must try to involve men in all nutrition education and child care activities. Public health officials must be deliberate about male involvement in breastfeeding promotion and protection through policy and implementation guidelines.

Even though this is a cross-sectional study and it utilized only quantitative methods, the findings depict the views and intentions of young men on male involvement in breastfeeding and particularly among undergraduate students. The authors, therefore, suggest a more exploratory study among a larger sample of young men to fully probe their views on breastfeeding, its protection, promotion, and support in Nigeria. The authors firmly believe this study provides a body of evidence on which sustainable interventions for male involvement in breastfeeding can be built.

\section{Conclusion}

The perception of breastfeeding among young undergraduate male students in this study was good and the willingness to support breastfeeding and its promotion at the individual and community levels was also evident. However, a lot more can be achieved through adequate stakeholder engagement. Workplace policies on maternity protection should encourage optimal breastfeeding. There is a need for health workers to consciously engage fathers and other adult males in the various educational interventions at all healthcare facilities in Nigeria.

\section{Declarations}

\section{Ethics approval}

Participation was fully voluntary and respondents were free to withdraw at any point during the study. Written informed consent was 
obtained from study participants. Strict confidentiality was ensured throughout the study. The study was entirely non-invasive and without any known potential to cause bodily or psychological harm to respondents. Approval was obtained from the health research and ethics committee of Olabisi Onabanjo University Teaching Hospital and affiliated medical school. We adhered strictly to the ethical guidelines of the Declaration of Helsinki.

\section{Consent for publication}

The authors hereby give consent for the publication of our work under the creative commons CC Attribution-Non-commercial 4.0 license.

\section{Conflict of interest}

The authors declare no conflict of interest.

Funding

No funding was received for the conduct of this study.

\section{Authors' contributions}

OOS conceptualized the study, OOS and POO designed the study, POO coordinated data collection and analysis, OOS and ITR drafted the manuscript. ITR read the manuscript for scientific cohesion. All authors approved the final draft of the submitted manuscript.

\section{Acknowledgments}

We appreciate greatly the assistance of Dr. Victor Animasahun and Dr. Korede Bankole Oyewole in the preparation of this manuscript.

\section{References}

1. Korenromp E, Wiistefeld M. Nutrition targets and indicators for the post-2015 Sustainable Development Goals. Accountability for the measurement of results in nutrition - a technical note. New York. UNSCN. 2015. Available from https://www.unscn.org/files/Publications/Po st 2015 Nutrition Targets and Indicators final March 2015 website .pdf Accessed on $4^{\text {th }}$ May 2020

2. Beluska-Turkan $K$, Korczak R, Hartell $B$, Moskal K, Maukonen J, Alexander DE et al. Nutritional gaps and supplementation in the first 1000 days. Nutrients. 2019; 11(12): 2891. Available from https://doi.org/10.3390/nu11122891 Accessed on $2^{\text {nd }}$ February 2020.

3. WHO. Infant and young child feeding model chapter for textbooks for medical students and allied health professionals. Geneva, Switzerland. World Health
Organization. 2009. Available from https://www.who.int/nutrition/publications/in fantfeeding/9789241597494/en Accessed on $2^{\text {nd }}$ February 2020.

4. IFPRI. Global Nutrition Report 2016. From Promise to Impact: Ending Malnutrition by 2030. Washington DC. International Food Policy Research Institute. 2016:182. Available from http://dx.doi.org/10.2499/9780896299948 Accessed on $4^{\text {th }}$ March 2020.

5. Ahmed KY, Page A, Arora A, Ogbo FO. Trends and determinants of early initiation of breastfeeding and exclusive breastfeeding in Ethiopia from 2000 to 2016. Int Breastfeed J. 2019; 14: 40 . Available at: https://doi.org/10.1186/s13006-019-0234-9 Accessed on $21^{\text {st }}$ March 2020.

6. Bhattacharjee NV, Schaeffer LE, Marczack LB, Ross JM, Swartz SJ, Albright J, et al. Mapping exclusive breastfeeding in Africa between 2000 and 2017. Nature Medicine. 2019. Available at: https://doi.org/10.1038/s41591-019-0525-0 Accessed on $27^{\text {th }}$ April 2020.

7. National Population Commission-Nigeria and ICF. Nigeria Demographic and Health Survey 2018. Abuja, Nigeria. NPC and ICF. 2019. Available at: https://www.dhsprogram.com/pubs/pdf/FR3 59/FR359.pdf Accessed on $3^{\text {rd }}$ June 2020.

8. Tampah-Naah AM, Kumi-Kyereme A, AmoAdjei J. Maternal challenges of exclusive breastfeeding and complimentary feeding in Ghana. PLoS ONE. 2019; 14(5): e0215285. Available at: https://doi.org/10.1371/journal.pone.02152 85 Accessed on $7^{\text {th }}$ January 2021.

9. Brown A, Davies R. Fathers' experiences of supporting breastfeeding: challenges for breastfeeding promotion and education. Maternal \& Child Nutrition. 2014; 10(4):510 - 526. Available at: https://doi.org/10.1111/mcn.12129

Accessed on $9^{\text {th }}$ December 2020.

10.Mitchell-Box K, Braun KL. Fathers' thoughts on breastfeeding and implications for a theory-based intervention. JOGNN. 2012; 41(6): $641-650$. Available at: https://doi.org/10.1111/j.15526909.2012.01399.x Accessed on $3^{\text {rd }}$ April 2020

11. Hansen E, Tesch L, Ayton J. 'They're born to get breastfeed' - how fathers view breastfeeding: a mixed-method study. BMC Pregnancy and Childbirth. 2018; 18: 238. Available

at: https://doi.org/10.1186/s12884-018-1827-9 Accessed on $22^{\text {nd }}$ June 2020. 
12.Mithani Y, Premani ZS, Kurji Z, Rashid S. Exploring fathers' role in breastfeeding practices in the urban and semi-urban setting of Karachi, Pakistan. J Perinat Educ. 2015; 24 (4):249-260. Available at: https://dx.doi.org/10.1891/1058-

1243.24.4.249 Accessed on 13th August 2020.

13.Dennis C, Brennenstuhi S, Abbas-Dick J. Measuring paternal breastfeeding selfefficacy: a psychometric evaluation of the Breastfeeding Self-Efficacy Scale - Short Form among Fathers. Midwifery. 2018; 64: 17 - 22. Available at: https://doi.org/10.1016/j.midw.2018.05.005 Accessed on $27^{\text {th }}$ June 2020.

14.Rempel LA, Rempel JK. The breastfeeding team: the role of involved fathers in the breastfeeding family. J Hum Lact. 2011; 27(2): 115 - 121. Available at: https://doi.org/10.1177/0890334410390045 Accessed on $26^{\text {th }}$ June 2020.

15.Bulemela J, Mapunda H, Snelgrove-Clarke E, MacDonald N, Bortolussi R. Supporting breastfeeding: Tanzanian men's knowledge and attitude towards exclusive breastfeeding. Int Breastfeed J. 2019; 14: 52. Available at: https://doi.org/10.1186/s13006-019-0244-7 Accessed on $24^{\text {th }}$ April 2020.

16.WHO/UNICEF. Innocenti Declaration on the Protection, Promotion, and Support of Breastfeeding adopted by policymakers at WHO/UNICEF meeting on 'Breastfeeding in the 1990s: A Global Initiative'. Florence, Italy. 1990. Available at: https://www.unicef.org/spanish/nutrition/ind ex 24807.html Accessed on $20^{\text {th }}$ May 2020.

17.Akadri A, Odelola $O$. Breastfeeding practices among mothers in Southeast Nigeria. Ethiop J Health Sci. 2020; 30(5): 697-706. Available at: https://dx.doi.org/10.4314/eihs.v30i5.8 Accessed on $12^{\text {th }}$ November 2020

18.Sankeir MJ, Sinha B, Chowdhury R, Bhandari N, Taneju S, Martins T, Bahi R. Optimal breastfeeding practices and infant and child mortality: a systematic review and meta-analysis. Acta Paediatr. 2015; 104 (467): 3 - 13. Available at: https://doi.org/10.1111/apa.13147 Accessed on $13^{\text {th }}$ May 2020.

19.UNICEF/WHO. Global breastfeeding scorecard 2017. Tracking progress for breastfeeding policies and programmes. New York. Global Breastfeeding Collective. United Nations Children's Fund / World Health Organization. 2017. Available at: https://www.who.int/nutrition/publications/in fantfeeding/global-bf-scorecard-2017/en/

Accessed on $5^{\text {th }}$ June 2020.

20.Adewuyi EO, Adefemi K. Breastfeeding in Nigeria: a systematic review. Int $\mathrm{J}$ Community Med Public Health. 2016; 3(2): 365-396. Available at: http://dx.doi.org/10.18203/23946040.ijcmph20160421 Accessed on $23^{\text {rd }}$ April 2020.

21. Roll Cl, Cheater F. Expectant parents' views of factors influencing infant feeding decisions in the antenatal period: a systematic review. Int J Nurs Stud. 2016; 60: 145-155. Int J Nurs Stud. 2016; 60: 145-155. Available

at: https://doi.org/10.1016/j.ijnurstu.2016.04.01 1 Accessed on 9th May 2020.

22. Áborigo RA, Moyer CA, Rominski S, Adongo $P$, Williams J, Logonia $G$, et al. Infant nutrition in the first seven days of life in rural northern Ghana. BMC Pregnancy and Childbirth. 2012;12:76. Available at: https://doi.10.1186/1471-2393-12-76

Accessed on $3^{\text {rd }}$ April 2020.

23.Sanusi RA, Leshi OO, Agada UN. Mothers' knowledge and practice of breastfeeding and complementary feeding in Enugu State, Nigeria. Journal of Research in Nursing and Midwifery. 2016; 5(1): 21-29. Available from https://doi.10.14303/JRNM.2015.127

Accessed on $18^{\text {th }}$ May 2020.

24.Sayers R. Breast is best: just maybe in private? British Journal of General Practice. 2014; 64 (618):44-45. Available from https://doi.org/10.3399/bigp14X676573

Accessed on 9th May 2020.

25.Samuel FO, Adepoju OT, Leshi OO. Knowledge and attitude of male staff in a Nigerian tertiary institution towards infant feeding. British Journal of Medicine and Medical Research. 2016; 12(1): 1-9. Available from https://doi.10.9734/BJMMR/2016/20348 Accessed on $17^{\text {th }}$ November 2020.

26.UNICEF. Infant and young child feeding: programming guide. New York. Nutrition section, Programmes. United Nations Children's Fund. 2012. Available at: https://sites.unicef.org/nutrition/files/Final I YCF programming guide 2011.pdf Accessed on $3^{\text {rd }}$ March 2020.

27. Omuemu VO, Adamu SA. Assessment of breastfeeding knowledge and practices among working mothers in the federal capital territory in Nigeria. International Journal of Community Medicine and Public Health. 2019; 6(1): $20-29$. Available at: http://dx.doi.org/10.18203/2394- 
6040.ijcmph20185222 Accessed on 7th April 2020

28.ILO. Maternity Protection Convention. Rome. C183. International Labour Organization. 2000. Available at: https://www.ilo.org/dyn/normlex/en/f?p=NO RMLEXPUB:12100:0::NO::P12100 ILO C ODE:C183 Accessed on $4^{\text {th }}$ June 2020

29.Xhuan NTT, Nhan NT. Breastfeeding experiences of working mothers in Vietnam. Belitung Nursing Journal. 2018; 4(3): 279 286. Available from https://doi.org/10.33546/bni.454 Accessed $22^{\text {nd }}$ July 2020.

30.UNICEF. Breastfeeding: Working mothers called for policy change to secure children's future. Timor-Leste. United Nations Children's Fund. 2018. Available at: https://www.unicef.org/timorleste/stories/br eastfeeding-working-mothers-called-policychange-secure-childrens-future Accessed on 21st February 2020

31. Chen J, Xin T, Gaoshan J, Qiuhong L, Zou $\mathrm{K}$, Tan S, Cheng Y, Liu Y, et al. The association between work-related factors and breastfeeding practices among Chinese working mothers: a mixed-method approach. International Breastfeeding Journal. 2019; 14:28. Available at: https://doi.org/10.1186/s13006-019-0223-z Accessed on $18^{\text {th }}$ May 2020.

32.WHO/UNICEF. Innocent Declaration 2005 On Infant and Young Child Feeding. Florence, Italy. World Health Organization / United Nations Children's Fund. 2005.
Available at: https://www.unicefirc.org/publications/435-innocentideclaration-2005-on-infant-and-youngchild-feeding.html Accessed on $3^{\text {rd }}$ May 2020.

33.Van Wagenen SA, Magnusson BM, Neiger BL. Attitude towards breastfeeding among an internet panel of US males aged 21- 44 . Matern Child Health J. 2015; 19:2020 $2028 . \quad$ Available at: https://doi.10.1007/s10995-015-1714-1 Accessed on $5^{\text {th }}$ June 2020.

34.Magnusson BM, Thackeray CR, Van Wagenen SA, Davis SF, Richards R, Merrill RM. Perceptions of public breastfeeding images and their association with breastfeeding knowledge and attitudes among an internet panel of men ages 21- 44 in the United States. Journal of Human Lactation. 2017; 33(1):157-164. Available at:

https://doi.org/10.1177/0890334416682002 Accessed on $26^{\text {th }}$ June 2021.

35.UNICEF/WHO. Breastfeeding and prevention of overweight in children advocacy brief. New York. Global Breastfeeding Collective. United Nations Children's Fund / World Health Organization .2020. Available at: https://www.globalbreastfeedingcollective.o $\mathrm{rg} /$ media/221/file/Breastfeeding\%20and\%2 Oprevention $\% 20$ of $\% 20$ overweight $\% 20$ in $\% 2$ 0children $\% 20-\% 20$ ENGLISH.pdf Accessed on $23^{\text {rd }}$ June 2020 